\title{
What would we Hear if we Really Listened? Using I-poems in Qualitative Marketing Research: An Abstract
}

\author{
Julie Robson and Caroline Burr
}

\begin{abstract}
Qualitative methods of analysis are concerned with transforming and interpreting data to capture and understand the complexities of the social world (Edwards and Weller 2012). However, the question that has preoccupied many qualitative researchers is how can we know, and how can we come to know, others who are a part of this social world (Doucet and Mauthner 2008).

The Listening Guide (LG) is a feminist, qualitative method developed by Brown et al. (1989) to enable researchers to hear how respondents uniquely make meaning of their social world (Woodcock 2005). It focuses on reconstructing the holistic meaning of the stories that people tell about themselves (Edwards and Weller 2012). I-poems are a fundamental component of the Listening Guide and centre on the relationship between the process of "selfing" (i.e., the activity of being a self) identified primarily through the use of "I" and knowing (Debold 1990). In I-poems, the collection of personal pronouns and the verbs/actions that go with them are presented in a format similar to that of a contemporary poem. I-poems have been recognised as an emergent method in social research (HesseBiber and Leavy 2006), and although the method has been extensively used by researchers in the field of psychology and sociology, only a small number of marketers have adopted this method (see for example Woodruffe-Burton and Brown 2015).

In this paper we provide an introduction to this innovative method and detail its application in a study conducted on the attitude young girls have to money. At conference we will share our findings and reflect on the contribution and insights that the use of I-poems can make in marketing by comparing and contrasting the findings from a thematic analysis with that using LG and I-poems. We will argue for the wider adoption of I-poems by fellow marketing academics.
\end{abstract}

Keywords Qualitative research · I-poems · Teenage girls · Money

References Available Upon Request

\footnotetext{
J. Robson $(\bowtie) \cdot$ C. Burr

Bournemouth University, Bournemouth, UK

e-mail: jrobson@bournemouth.ac.uk; cburr@bournemouth.ac.uk
}

(C) The Academy of Marketing Science 2020

S. Wu et al. (eds.), Marketing Opportunities and Challenges in a Changing Global Marketplace, Developments in Marketing Science: Proceedings of the Academy of Marketing Science, https://doi.org/10.1007/978-3-030-39165-2_4 